\title{
Franco-American Teachers-in-Training: A Study of Best Practices in Teaching and Studying Abroad
}

\section{Susan Colville-Hall}

University of Akron

\section{Maria Adamowicz-Hariasz}

University of Akron

\section{Vladislava Sidorova}

University of Akron

\section{Tama Engelking}

Cleveland State University

\section{Introduction}

Study abroad is generally recognized as a transformational experience for university students to help prepare them to be what many in higher education are now calling "global citizens." Responding to the need to prepare citizens for the interconnected global world of the 21st century, K-12 educators recently established new standards and benchmarks to ensure learners become internationally competent (Colville-Hall \& Adamowicz-Hariasz, 2010; NCSS, 2010). But how do U.S. teachers themselves reach levels of intercultural competence?

Is living or studying abroad sufficient to provide the transformative linguistic and cultural experience future educators need to be able to cope with the cultural diversity of learners who come from backgrounds increasingly different from that of the majority of their teachers? As professionals, teachers tend to have the least intercultural experience (Cushner, 1998; Karaman and Tochon, 2010). In the case of prospective teachers, study abroad can take the form of an international student teaching experience that engages them in cross-cultural encounters essential to intercultural learning.

A defining characteristic of the global citizen is intercultural competence, something that college students will supposedly achieve through study abroad. As students study abroad in greater and greater numbers, the emphasis on 
assessment and accountability that prevails at many universities demands evidence that learning goals such as increased intercultural competence and improved language skills are being met. Study abroad advocates are looking specifically at ways to help students make the most of their time abroad, and are using tools such as the Intercultural Development Inventory (IDI) to quantify the success of study abroad programs. The Franco-American Teacher in Training Institute (FATITI) offers one example of a program design that resulted in both increased intercultural sensitivity and improved language skills among the participants as measured by the IDI and oral proficiency scores.

\section{Franco-American Teachers-in-Training Institute}

The University of Akron's Franco-American Teachers-in-Training Institute (FATITI), now in its fifth year, is an initiative to help teachers expand crosscultural knowledge and develop a global perspective necessary for teaching in the $21^{\text {st }}$ century. Teacher interns from France come to northeast Ohio from January to March to learn more about U.S. education and to teach in U.S. schools. American teacher interns spend three and a half months each fall in French schools collaborating with a mentor and teaching their content area in French.

Essentially, FATITI promotes collaboration between mentors and preservice teachers at an international level, encourages them to examine and use best instructional practices, and helps them develop into internationallyminded educators that impact student learning in ways that will insure their students' participation in the interconnected global arena. Working in close cooperation with the U.S. Department of State, the French Ministry of Education, the CDIUFM (Conference of Directors of the University Institutes for Teacher Education), and the Franco-American Commission, each year FATITI offers a new group of young professionals on both sides of the Atlantic a three-week seminar followed by a 9-week internship in area schools.

For the purposes of this study, we limited the focus to the group of American pre-service teachers who taught in France from September to December 2009. We chose the American participants in order to compare our results with similar programs designed for American students studying abroad. It would be impossible to draw valid and reliable comparisons between the US and French programs because the two exchanges are very different. FATITI recruited candidates throughout the U.S. in science, math, language arts, foreign languages and social studies, who were in the final stage of their teacher education program and who had obtained at least a basic level of French proficiency (novice high on the ACTFL/OPI scale). 


\section{Intercultural Development Inventory}

In order to assess the degree of acquisition of intercultural competence of group participants, we selected the Intercultural Development Inventory (IDI) for pre- program and post-program measures. Based on Bennett's Developmental Model of Intercultural Sensitivity (DMIS) (Bennett, 1993), the IDI was developed in 1998 by Mitch Hammer and Milton Bennett. It is an empirical standardized tool that can be factored into the pre- and post- assessment of study abroad programs to measure gains in intercultural sensitivity as a predictor of intercultural competence. The IDI is a 50-item instrument that produces a Developmental Score to describe the way cultural difference is perceived in terms of six developmental stages that move from an ethnocentric worldview-Denial, Defense/Reversal and Minimization-toward a more complex or ethnorelative way of perceiving cultural difference-Acceptance, Adaptation and Integration. It is considered to be one of the most robust tools available to measure intercultural sensitivity and its validity and reliability have been repeatedly demonstrated in a number of different studies such as the assessment conducted by Paige, Jacobs-Cassutuo, Yershova, and DeJaeghere (2003).

The Franco-American Teachers in Training Institute (FATITI) builds on previous studies that have used pre- and post- IDI testing with a specific focus on identifying program characteristics that contribute to intercultural learning. In particular, we refer to the seven defining components identified by Engle and Engle in 2003, and more recently tested by Vande Berg, Connor-Linton and Paige (2009) in the Georgetown Consortium Study. Our assessment results and the design of the FATITI program reinforce the conclusions of Vande Berg and others who see active intercultural interventions as perhaps the single most important factor to assure that intercultural learning takes place abroad. These interventions play a role in balancing out the challenges of study abroad with the appropriate level of support to maximize intercultural growth in the context of study abroad, or in the case of FATITI, teaching abroad.

\section{Methods and Results}

This study examines a group of pre-service teachers who participated in FATITI in Fall 2009. 16 American teachers-in-training traveled to France to partake in a three-week seminar followed by a nine-week practicum where they were placed in French schools with mentor teachers in the area of their discipline. The Intercultural Development Inventory (IDI) was administered to the group at the beginning of their experience abroad and after they had completed the program. Among FATITI participants, the IDI results reveal an increase in the mean gain for the group of 11.29 points. This represents a 
greater increase than the results reported for Georgetown Consortium study (Vande Berg, Connor-Linton and Paige, 2009) in which over 1,300 American students studying abroad averaged a gain of 2.33 points on the IDI.

This report analyzes the structure of the FATITI program and compares it with the factors identified in literature as contributing to greater increases in intercultural development.

Sanford (1966) identifies the best model to promote intercultural development as one that provides both support and challenge to the student. The design of FATITI program exemplifies the "challenge/support" model for study abroad in that teachers-in-training are direct participants in the educational institutions of their host cultures who are also housed with host families. The participants receive ample support and preparation before and during their experience in the form of regular meetings with mentor teachers, a pre-departure orientation and follow-up session at the end of their program. Teachers-in-training are required to reflect on their experience in writing at all stages, and also to participate in individual and group interviews. An additional feature is the program's comparative focus seeks to identify practices in the educational system of the host culture that participants can adapt for their own classrooms back home.

Fourteen of the sixteen participants in the 2009 Franco-American Teachers-in-Training Institute took the IDI before and after completing a 15-week program in France. Eleven of them showed gains in intercultural learning as measured by their pre- and post IDI results with scores ranging from a 3.91 increase to 29.01 point increase. While three of the participants' scores decreased, $79 \%$ of the group increased their intercultural sensitivity. Seven of the eleven whose scores indicated intercultural growth changed levels as measured on Bennett's Developmental Scale of Intercultural Sensitivity (Bennett, 1993). Five of those participants who began in the Minimization phase, tested in the Acceptance phase at the end of the 15-week program in France. One participant went from the Acceptance to the Adaptation phase and another, whose initial score was in the Polarization stage, ended in Minimization. As a group, the mean change between pre- and post IDI results was an increase of 11.29 points.

The FATITI results are much higher than those recorded by Vande Berg et al (2009) in the Georgetown Consortium study for study abroad programs of similar duration (13-18 weeks). According to Vande Berg'et al's findings, the average pre-trip IDI score was 96.02 for students in 13-18 week programs with participants increasing their IDI scores on a post-study abroad IDI by 3.398 points (post-trip average of 99.42). The FATITI results suggest that the program design was highly effective for increasing the participants' intercultural 
proficiency. At the same time, caution should be exercised when interpreting these numbers. The small sample size used in this study, due to the nature of the program, has the potential of impacting the statistical significance of the findings. Therefore, comparisons between the 2009 FATITI and other study abroad programs should be drawn with care until more IDI data are available from subsequent FATITI participant groups. (NB: The 2009 U.S. participants were the first group to take the IDI). Nevertheless, the sizeable increase in intercultural competence as measured by the pre- and post IDI scores of the 2009 FATITI participants warrants a closer examination of the program design including such elements as participant language proficiency levels, support in country (mentoring), housing situations, and social context.

\section{The Franco-American Teachers-in-Training Program Design}

The University of Akron's Franco-American Teachers-in-Training Institute (FATITI) is not a typical study abroad program, but certain aspects are identical. It is an immersion-type experience in foreign language and culture with learning outcomes similar to other study abroad programs. FATITI is an initiative to help teachers expand cross-cultural knowledge and develop a global perspective necessary for teaching in the 21 st century. American teacher interns spend three and a half months in French schools collaborating with a mentor to learn more about the French language, culture and educational system.

FATITI program goals intend to:

- Promote acquisition of knowledge, cross-cultural experience, problem-solving skills, and flexibility,

- Advocate the necessity of global agents who work to find better solutions to universal educational challenges,

- Foster development of productive, engaged and critical citizens,

- Encourage citizen diplomacy, dispelling naïve cultural stereotypes,

- Advance professional growth and development in teaching research and service in international and cross-cultural education.

Because FATITI is a federally funded program, evaluation measures were established to assess the effectiveness of program components and have been in use every year since 2007. These evaluation tools also serve as a means to measure progress of the participants in terms of the program goals that were set. They include follow-up surveys after each component of the program (seminar, cultural visits and teaching practicum), journal prompts, individual teaching evaluations, and debriefing sessions. We added the Intercultural Development Inventory (IDI) as an assessment tool in the second half of the $3^{\text {rd }}$ year. In 
addition, we use other sources such as reports by visiting French delegations, anecdotal information, personal correspondence and administrative notes.

The data collected in Fall 2009 provided insights into the program's success in achieving the following goals:

1. Help teachers to acquire knowledge and meet student needs;

2. Encourage teachers to become global agents by developing citizen diplomacy and broadening their world view; and

3. Enable professional growth in teaching, research and service in international and cross-cultural education.

Survey and journal prompt data demonstrate that the U.S. teachersin-training developed greater effectiveness in instruction, management, and assessment through examination of a culturally different pedagogy and through their experience in a culturally different classroom. We also have evidence that suggests an increasingly more complex world-view among our participants as they move toward ethnorelativism. As a result of the program, the FATITI participants are better equipped to be global change agents, who will continue to network in order to find solutions to improve learning outcomes for their students. Not only do we have an intercultural competence assessment but also evidence of linguistic growth. The Oral Proficiency Interview (OPI) preand post-program ratings revealed as much a 4 sub-level jump for certain participants and at least one sub-level increase for all who completed both interviews

\section{Defining elements of a study abroad program}

What aspects of FATITI can account for these gains in pedagogical, intercultural and linguistic competence? Vande Berg et al (2009), in examining multiple studies, found a correlation between the seven defining elements of study abroad programs reported by Engle and Engle (2003) and the increase in student learning: 1) duration of the study, 2) pre-departure second language proficiency, 3) language used in coursework, 4) the context of academic work, 5) housing factor, 6) guided or structured experiential activities, 7) guided reflection about experience abroad.

Vande Berg er al(2009) argue that a program needs to have these seven elements to be successful in providing a learning experience abroad. These components played a central role in the design of the FATITI experience. According to Engle and Engle (2003), one of the first critical elements in program effectiveness is the duration of study abroad. For U.S. pre-service teachers, FATITI lasted from September to mid-December, long enough for 
participants to immerse themselves in the local community. A second crucial element identified by Engle and Engle, the pre-departure second language proficiency, is part of the FATITI admission requirements. In 2009, all U.S. candidates had to have a novice high French oral proficiency on the ACTFL scale, while in 2010, the requirement was raised to the intermediate low level.

The language used in coursework abroad and the context of the academic work abroad are the third and fourth components found to have an impact on learning outcomes (Engle \& Engle, 2003). FATITI participants go through an intensive three-week French language immersion program in Besançon, France, prior to their teaching practicum in French schools, and are expected to use French in their host schools and Instituts Universitaires pour la Formation des Maitres (IUFMs) where they take teacher-training courses. Thus, the FATITI experience offered participants an immersion type of academic setting that includes French-speaking teachers, students and staff, all requiring FATITI pre-service teachers to interact with a variety of French individuals as part of their professional life.

Engle and Engle (2003) highlighted the housing situation as an equally important factor in increasing intercultural competence. International students benefit from being surrounded by a rich linguistic environment where others take an interest in their lives. At the beginning, FATITI participants were placed in apartments, dorms, and a few host families, but the program staff has always advocated host families. As a result, the number of pre-service teachers placed with host families has significantly increased. In 2009, the majority of participants stayed with host families, while the remaining few were assigned university housing. In 2010, all but one participant stayed with host families. FATITI participants hosted by families identified the host setting as responsible in large part for linguistic improvement and new cultural knowledge due to continued immersion in the language and culture.

The impact of student participation in guided/structured experiential activities was identified by Engle and Engle as another important element. Both the seminar and practicum portions of the FATITI experience addressed this essential component. Visiting French schools during the seminar sessions in Besançon, teaching with a French mentor for eight weeks, meeting with IUFM supervisors as part of the observation process, as well as attending classes at the French colleges of education constituted a wide range of guided activities.

Finally, Engle and Engle (2003) emphasized the importance of how often the staff provides "guided reflection on student experience" (as cited in Vande Berg, et al 2009, p. S22), which refers to "on-site meetings during which faculty or resident staff help student de-brief and reflect on their 
intercultural learning" (as cited by Vande Berg, 2009, p. S18). Since FATITI program directors/administrators where not physically with participants, they provided this "cultural mentoring" (Vande Berg, 2009, p. S21) long distance via emails, with occasional phone calls, journals prompts and a final on-site visit. FATITI participants collaborated closely with mentor teachers in France and IUFM contacts, but their contact focused mostly, if not exclusively in certain cases, on teaching (methods, assessment, lesson plan). Pre-service teachers were especially encouraged to reflect on intercultural learning through journaling and debriefings with the program staff. Journal prompts were designed to address the following intercultural competency aspects: setting personal and professional goals, developing a sense of belonging, increasing linguistic proficiency, dealing with challenges and stress, and establishing professional networks. As a direct way to process and reflect on experiential activities, journaling became a primary means of active intervention in the students' learning, a phenomenon recognized as effective by the Georgetown Consortium study (Vande Berg, et al 2009).

As replacement of a cultural mentor in situ, journal prompts are not always an ideal tool since participation is voluntary and there is no immediate feedback and often no feedback at all. However, journal prompts can be an effective instrument in reflection, articulation and self-assessment processes vital for the intercultural development.

According to Vande Berg, "If study abroad's unique potential is to be met, we need to intervene actively in our students' learning--before, during, and after their experience abroad" (2007, p. 392). For our program, journaling started before the participants left for France, the first prompt being assigned during the first big block of intervention, a three-day pre-departure seminar at the University of Akron. This first series of interventions was followed by the second block, a three-week language and culture seminar in Besançon, France, that preceded the main part of the program - teaching in French schools. Both blocks offered a good combination of challenge and support as recommended by Sanford (1966).

\section{Preparation for the FATITI Experience}

Two components of FATITI, the pre-departure orientation in Akron, Ohio, and the seminar at Besançon's Centre Linguistique Appliquée (CLA) in France, provided participants a firm foundation for future linguistic and cultural acquisition. Detailed descriptions of those components offer insight into the richness of the FATITI preparation.

Pre-departure orientation. Three months ahead of the orientation in Akron, the participants were assigned homework. They were required to read 
Sixty Million Frenchmen Can't Be Wrong, by Nadeau and Barlow, 92003) in which the authors examine French history and culture in an attempt to explain this modern country full of contradictions. The participants were asked to take detailed notes and to write a paragraph of ten sentences beginning with the phrase "According to the authors of the book, the French are..." followed by their own comments, agreements or disagreements with the authors based on their knowledge from other sources (books, films, travels). In the case of little to no prior knowledge of France and/or the French, they were expected to write a few questions they would like to ask to further clarify the book's statements. Also required were selected articles in French and in English about the French education system, its history and current issues. Again participants were required to write down specific questions to ask during the pre-departure orientation in Akron. French movies taking place in a school environment were suggested to watch as well to help the participants better understand and imagine their life in France. (Argent de poche (Small Change), 1976; Etre et avoir (To Be and To Have) (documentary) 2002; Le plus beau métier du monde, 1996). Other suggestions included watching the French news, reading regularly Le Monde in order to keep abreast of current events in France and to help them better understand the news viewed on the internet; watching the news/reading papers in the U.S. to stay informed about the events in their own country too; sharing questions/observations with other participants before the actual seminar by sending their entries to the web site established for the group's discussion. In addition, all the participants also received via regular mail a special packet containing practical information such as contact list (addresses, emails of all the personnel involved in France and the U.S.), tips from alumni of the program (what to do/not to do before leaving for France and in France), travel tips for France and helpful websites.

After taking care of the necessary administrative issues on Day 1 of the pre-departure orientation, we concentrated on lively and lengthy debates based on the readings assigned. Discussions answered many of the participants' questions but also raised additional ones, demonstrating the ambiguity and uncertainty they were facing in the weeks and months ahead.

The first part of the Day 2 was devoted to brushing up on basic knowledge, skills and behaviors necessary for a longer stay in France. Quick review of current events, influential people, dominant social issues, holidays, and savoirvivre was followed by a series of activities about cultural misunderstandings that emphasized the necessity to suspend judgment and be flexible, to expect miscommunications and misunderstandings, and to be aware of one's own cultural biases and assumptions. The afternoon session of Day 2 was spent on goal setting. According to Vande Berg, "educators need to intervene [...] 
by helping students identify their own and program learning goals and by formatively assessing their efforts to meet those goals (Vande Berg 2009, pp. S25-S26). Handouts based on the book Study Abroad by Dowell and Mirsky (2003) were prepared to help participants articulate their specific personal and professional goals, brainstorm about ways to learn/achieve these goals, anticipate obstacles and establish frequency of possible activities. The participants worked in small groups on the forms to fill them out and to share them with others or to keep them for themselves. These various activities were intended to act as a kind of road map to help participants navigate in the unknown territory, not to get too distracted or upset about roadblocks, and keep their eyes on their personal goals.

We believe this kind of a pre-departure exercise in learning abroad prepared the participants to think ahead and helped them to open up to a whole range of new experiences. Most of all, it gave them a necessary structure to use and encouraged them to interact with the French. Once placed at their school site, our participants were often alone in their respective schools and cities, and the need of a cultural mentor-a mediator between the two cultures and the one whose role is to intervene and encourage the students to actively engage in experiential activities - was then played by our journal prompts. Towards the middle of the program, for instance, we asked our participants to revisit their personal, professional and linguistic goals and ask themselves if they are satisfied with what they've accomplished and if not, what can they do about it. The coordination of the pre-departure goal setting and problem solving activities with subsequent reminders in the form of journal prompts was crucial, in our view, to achieving the remarkable gains in the intercultural development for most of our participants. Akron pre-departure orientation challenged the students to face the unknown, to expect the unexpected, to accept ambiguities, to withhold judgments while at the same time offered supporting tools to help them navigate cultural conflicts.

Language and Culture Seminar in France. The three-week seminar took place at the Centre de Linguistique Appliquée, in Besançon, France. The wellknown and highly regarded center was carefully chosen by our French partners after a competitive bid that followed a very specific enumeration of needs and requirements involving three key aspects: introduction to French culture and to the French educational system and an intensive French language training.

The introduction to the French educational system (in English or French with English translation) involved meetings and receptions with city administration representatives, lectures by French teachers and administrators from local schools as well as representatives of the French Ministry of Education, access to a website and other forms of documentation for further 
consultation. School visits and observations were an integral part of the seminar and included field trips to a variety of different types of local middle and high schools, including ZEP schools (zone d'education prioritaire or schools with students "at risk") and another European model, a Franco-German dual language secondary school in Freiburg, Germany.

Group language practice took place in small groups in the form of conversation classes. These classes were divided into two groups according to the level of their proficiency in French and focused mainly on oral production and comprehension. Participants spent between two and four hours a day in their conversation groups and frequently changed instructors. Participants were also required to spend between one and one and a half hours a day in the language resource center focusing on individual work which was selfdetermined by each participant according to his or her own needs and interests. Linguistic and cultural immersion were achieved through living with host families, outings with Erasmus students and other CLA students, guided tours and self-discovery of the city and region, and participation in city-wide events such as an International Music Festival and Journées du Patrimoine. Additional cohesion of the group was created through common lunch in the university cafeteria and weekend trips to neighboring cities and towns like Arbois and Dijon, as well as museums and cultural and historical landmarks like The Arc-et-Senans and the Chateau de Jeux.

The initial shock of cultural and linguistic immersion can be difficult for anybody undergoing such an experience, but the seminar in Besançon lessens the impact of being in a new culture for participants by permitting a more gradual immersion. The presence of the entire group in one place before splitting up to their individual teaching posts provides a sense of comfort as participants gradually become accustomed to living and working in another culture. The city of Besançon is home to both the aforementioned CLA as well the University of Franche-Comté. Both of these institutions attract international exchange students and thus the local community is more accustomed to and accepting of foreign students than one might find in other cities in the region. The familiarity of the community with exchange students benefited the homestay experience as well; few participants were hosted by families who had never accommodated exchange students in the past, and several participants even had other exchange students staying with their host families during their stay.

The totality of FATITI interventions before and during the program (two seminars, journaling) exemplifies the "challenge/support" model suggested by Sanford (1966) and recommended by Vande Berg (2009, p. S21). Vande Berg argues that "educators need to intervene and provide support in challenging 
learning environments" (2009, p. S22). For our program, the two big blocks of intervention in the form of two seminars, the pre-departure orientation in the U.S. and the language and culture seminar in France, provided a good combination of support/challenge necessary for intercultural growth and learning, and prepared the participants for the independent discovery of, and coping with, cultural dissimilarities. All the interventions helped our participants develop the intercultural concepts and skills that became "the tools to learn effectively in another culture” (Vande Berg, 2007, p. 398).

\section{Conclusion}

For future teachers such as those who have participated in FATITI, the intercultural competence they achieve abroad can help prepare them to meet the challenges of the increasingly diverse student population they will encounter in their classrooms when they return home and to be more capable of preparing citizens for the interconnected world of the 21 st century. Thanks to standardized assessment tools such as the IDI, educators have been able to gather data that points to some of the best practices in study abroad for developing intercultural competence. FATITI has contributed to those ongoing assessment efforts, reinforcing the need to design study abroad programs that challenge our students to engage with the host culture, while providing them with the appropriate support to make the most of their new experiences. As we fine-tune the support elements of the FATITI program, we eagerly await the post IDI results of the 2010 FATITI group to see if it replicates the impressive gains in intercultural competence seen in the 2009 FATITI participants.

\section{References}

Bennett, M. (1993). Towards ethnorelativism: A developmental model of intercultural sensitivity. In R. M. Paige (Ed.), Education for the intercultural experience (pp. 21-71). Yarmouth, ME: Intercultural Press. Colville-Hall, S., \& Adamowicz-Hariasz, M. (2010). Going global, a requirement for the $21^{\text {st }}$ century: How teacher candidates and a community benefit from teachers abroad. Ohio Social Studies Review, $46,48-55$.

Cushner, K. (1998). International perspectives on intercultural education: An integrative approach. Mahwah, NJ: Lawrence Erlbaum Associates, Inc.

Dowell, M.-M., \& Mirsky, K. P. (2003). Study abroad: How to get the most out of your experience. Upper Saddle River, NJ: Prentice Hall. 
Engle, L., \& Engle, J. (2003). Study abroad levels: Toward a classification of program types. Frontiers: The Interdisciplinary Journal of Study Abroad, 9, $1-20$.

Hammer, M.R., \& Bennett, M. J. (1998/2004). The intercultural development inventory (IDI) manual. Portland, OR: Intercultural Communication Institute.

Karaman, A. C., \& Tochon, F. V. (2010). Worldviews, Criticisms, and the Peer Circle: A Sstudy of the experiences of a student teacher in an overseas school. Foreign Language Annals 43 (4), 583-604.

Nadeau, J.-B., \& Barlow, J. (2003). Sixty million Frenchmen can't be wrong: Why we love France but not the French. Naperville, IL: Sourcebooks. National Council for Social Studies. (2010). National curriculum standards for social studies: A framework for teaching, learning, and assessment. Silver Spring, MD: National Council for Social Studies.

Paige, R. M., Jacobs-Cassutuo, M., Yershova, Y.A. \& DeJaeghere, J. (2003). Assessing intercultural sensitivity: An empirical analysis of the Hammer and Bennett Intercultural Development inventory. International Journal of Intercultural Relations, 27, 467-486.

Sanford, N. (1966). Self and society: Social change and development. New York: Atherton Press.

Vande Berg, M. (2007). Intervening in the learning of U.S. students. Journal of International Education, 11, 392-399.

Vande Berg, M. (2009). Intervening in student learning abroad: A researchbased inquiry. Intercultural Education ,20, 15-27.

Vande Berg, M., COnnor-Linton, J., and Paige, R.M. (2009). Interventions for student learning abroad.Frontiers: The Interdisciplinary Journal of Study Abroad, 18, 1-75 
Appendix

Handout on Setting Linguistic Goals

Learning French

What are your personal goals in language learning? Be specific in what you want to achieve and how. Make a list: Goals/Steps in Reaching Goal(s).

Consider the following categories:

-listening comprehension

-reading comprehension

-speaking

-writing

-vocabulary development

-pronunciation

-ability to understand slang

-fluidity of speech

In order to improve skills, I will (activities) (frequency).

\section{Possible roadblocks to achieving language-learning goals:}

-the French will want to speak English with you

-you will want to fall back on the comfort and ease of your native language speaking with your fellow participants/other foreigners

-modern technology (Facebook, Skype...)

$-?$

Possible solutions for these challenges: 